http://jmscr.igmpublication.org/home/ ISSN (e)-2347-176x ISSN (p) 2455-0450

crossref DOI: https://dx.doi.org/10.18535/jmscr/v8i11.74

Journal Of Medical Science And Clinical Research

\title{
Study on Microalbuminuria in Newly Diagnosed Hypertensive Patients
}

Authors

Marrapu Venkata Vivek ${ }^{1 *}$, Dr K Indira Devi MD², Dr T Manasa ${ }^{3}$, Dr Y Pranathi ${ }^{4}$

${ }^{1,3,4}$ Postgraduate in General Medicine, Department of General Medicine, Andhra Medical College, KGH, Vizag

${ }^{2}$ Professor, Department of General Medicine, Andhra Medical College, KGH, Vizag

*Corresponding Author

Marrapu Venkata Vivek

\begin{abstract}
Background: Hypertension is one of the most frequent diagnosis in hospitalized/outpatients in our country with significant morbidity and mortality. Microalbuminuria has important cardiovascular implications in hypertensive patients. It is known to occur independently in diabetes mellitus and hypertension. Microalbuminuria is an independent risk factor of target organ damage like hypertensive retinopathy, abnormality of left ventricular function. It indicates the severity of the disease and has been considered an important prognostic indicator.

Objectives

* To observe microalbuminuria in newly diagnosed hypertensives

\& To study the relationship between microalbuminuria and target organ damage(left ventricular hypertrophy)

Hundred hypertensive cases are evaluated for microalbuminuria. Microalbuminuria was measured in these patients by immunoturbidimetric assay.

Results: Significant microalbuminuria was observed to occur in hypertensive patients. The prevalence of microalbuminuria in this study is $32 \%$. A positive correlation is noted between microalbuminuria and target organ damage. It was observed that there is a significant correlation between the prevalence of microalbuminuria and the presence of $L V H(P<0.05)$ in hypertensive patients.

Conclusion: Significant microalbuminuria was found to occur in newly detected hypertensive patients. This positive correlation between microalbuminuria and target organ damage in hypertensive patients calls for further studies with greater sample size.

Keywords: Microalbuminuria; Hypertension; Target organ damage.
\end{abstract}

\section{Introduction}

Hypertension is one of the major public health problems throughout the world.

Hypertension is estimated to cause $14 \%$ of total deaths. Blood pressure levels are positively related to the risk of stroke and coronary heart disease. In addition to coronary artery diseases and stroke, complications include heart failure, peripheral vascular disease, retinal hemorrhage, visual impairment, and renal impairment. Maintaining systolic and diastolic blood pressure less than $140 / 90 \mathrm{mmHg}$ is associated with a reduction in complications. 
Primary hypertension produces clinical proteinuria and a notable reduction in renal function in 5 to $15 \%$ of patients. The advent of sensitive methods to quantify urinary albumin excretion (UAE) has revealed a higher prevalence(25-100\%) of microalbuminuria in patients with hypertension compared to normotensives.

According to the National Kidney Foundation Microalbuminuria is defined as a Urine Albumin Excretion Rate (UAER) of approximately 30$300 \mathrm{mg} / \mathrm{d}$ in at least two of three consecutive samples of nonketotic sterile urine. The relation between hypertension and microalbuminuria was described a long time ago. In 1976, Parving et al highlighted the association between the severity of hypertension and microalbuminuria. Microalbuminuria indicates a state of increased renal endothelial permeability. It is an easily measured marker of low-grade inflammation, diffuse endothelial dysfunction, and vascular disease burden. Hence, screening for microalbuminuria and follow up of patients is now a general practice in some countries, but not all.

\section{Aims and Objectives}

1. To observe microalbuminuria in newly diagnosed hypertensives

2. To study the association between microalbuminuria and target organ damage (left ventricular hypertrophy)

\section{Materials and Methods}

Study Area: Department of General Medicine, Andhra medical college, Visakhapatnam, Andhra Pradesh.

Study Population: The study was performed among the patients admitted in medical wards and those attending the medical Out-Patient Department of general medicine, Andhra medical college, Visakhapatnam.

Study Period: Approximately 9months from January 2020 to September 2020.

Sample Size: Total of 100 patients who were newly diagnosed with hypertension was taken into study.
Sample design: Having had informed consent for participation from the patient and/ or patient caregiver, the patient was included in the study according to the following criteria.

Study Design: a cross-sectional study

\section{Inclusion Criteria}

1. Patients who are newly detected with hypertension with systolic BP $>130 \mathrm{mmHg}$ and/or diastolic $\mathrm{BP}>90 \mathrm{mmHg}$ in at least 3 visits.

2. Age of more than or equal to 18 years.

\section{Exclusion Criteria}

1. Patients with age $<18$ years of age.

2. Patients with Diabetes Mellitus: Either history of diabetes or those newly detected. [FBS $\geq 126 \mathrm{mg} / \mathrm{dl} ; 2 \mathrm{hr}$ PPBS $\geq 200 \mathrm{mg} / \mathrm{dl}]$

3. Patients with a previous history of Ischemic Heart disease or any other congenital/ acquired heart diseases.

4. Patients with Albuminuria or history of any renal disease or any other Target organ diseases.

5. Patients with raised serum creatinine [>1.5 $\mathrm{mg} / \mathrm{dl}]$ or urine examination showing RBC, WBC, or urine $\mathrm{C} \& \mathrm{~S}$ yielding bacteria.

\section{Statistical Method}

A chi-square test was used to study the relationship between microalbuminuria and other variables. The $\mathrm{p}$-value was calculated for all the variables.

For those variables with significant P-value, the odds ratio was calculated

\section{Statistical Software}

The statistical software namely social statistics was used for the analysis of the data and Microsoft Excel, and word have been used to generate graphs, tables, etc

\section{Investigations did include}

1. Fasting and Postprandial blood sugar

2. Serum creatinine 
3. Complete Urine examination

4. Lipid profile

5. Electrocardiogram: was done for all cases to look for LVH. The Sokolow - Lyon Index and the Romhilt - Estes point score system was used to diagnosing LVH. Those patients who meet the criteria of either of these were regarded as having LVH.

6. Chest X-ray: was taken in all patients to look for cardiomegaly.

7. Echocardiogram: Done to assess LVH.

8. Urine albumin creatinine ratio(ACR) based on the recommendations of the National Kidney Foundation and American Diabetic Association

The average of the ACR values from 3 urine samples was used.

Early morning 1st voided midstream urine sample of $5 \mathrm{ml}$ collected.

Any value in between $30-300 \mathrm{mg} / \mathrm{gm}$ or 3 $30 \mathrm{mg} / \mathrm{mmol}$ Creatinine was taken as microalbuminuria.

\section{Results}

32 out of 100 patients had microalbuminuria.

\begin{tabular}{|c|cc|cc|}
\hline \multirow{3}{*}{} & \multicolumn{3}{c|}{ Microalbuminuria } \\
\cline { 2 - 5 } TOTAL & \multicolumn{2}{c|}{ Absent } & \multicolumn{2}{c|}{ Present } \\
\cline { 3 - 5 } 100 & No. & $\%$ & No. & $\%$ \\
\hline
\end{tabular}

With increasing severity of hypertension, prevalence of microalbuminuria increases as there is significant $\mathrm{P}$-value.

\begin{tabular}{|c|c|c|c|c|c|}
\hline \multirow{4}{*}{$\begin{array}{l}\text { Stage of } \\
\text { hyperten } \\
\text { sion }\end{array}$} & & \multicolumn{4}{|c|}{ Microalbuminuria } \\
\hline & \multirow[b]{3}{*}{ TOTAL } & \multicolumn{4}{|c|}{$P=0.00614$} \\
\hline & & \multicolumn{2}{|c|}{ Absent } & \multicolumn{2}{|c|}{ Present } \\
\hline & & No. & $\%$ & No. & $\%$ \\
\hline $\begin{array}{l}\text { High } \\
\text { Normal }\end{array}$ & 14 & 12 & 85.7 & 2 & 14.2 \\
\hline Stage I & 31 & 26 & 83.8 & 5 & 16.12 \\
\hline Stage II & 55 & 30 & 54.5 & 25 & 45.45 \\
\hline
\end{tabular}

It was observed that 32 out of 100 patients had LVH [32\%] detectable by ECHO. 16 out of 28 with LVH had MA (57.1\%).

RELATIVE RISK OF DEVELOPING LVH IN PATIENTS WITH MICROALBUMINURIA

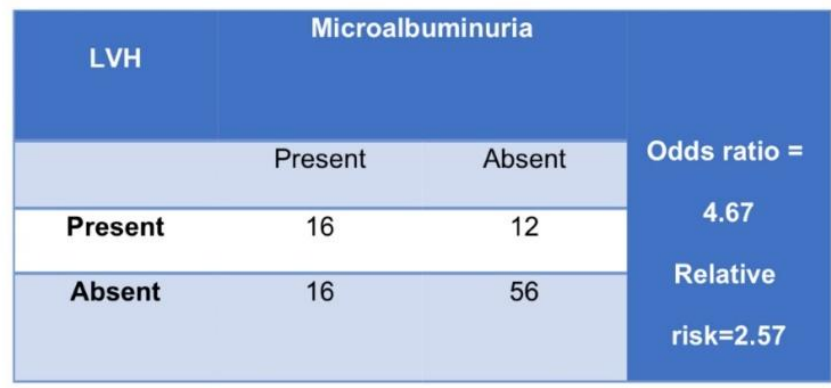

LVH AND MICROALBUMINURIA IN STUDY SUBJECTS

\begin{tabular}{|c|c|c|c|c|c|c|}
\hline \multirow[b]{3}{*}{ LV H } & \multirow[b]{3}{*}{ Total No. } & \multicolumn{4}{|c|}{ Microalbuminuria } & \multirow{3}{*}{$\begin{array}{c}X^{2} \\
=11.2979 \\
P=\end{array}$} \\
\hline & & \multicolumn{2}{|c|}{ Absent } & \multicolumn{2}{|c|}{ Present } & \\
\hline & & $\begin{array}{c}\text { No of } \\
\text { patients }\end{array}$ & $\%$ & $\begin{array}{l}\text { No of } \\
\text { patients }\end{array}$ & $\%$ & \\
\hline Absent & 72 & 56 & 77.77 & 16 & 22.22 & 0.000776 \\
\hline Present & 28 & 12 & 42.85 & 16 & 57.14 & \\
\hline
\end{tabular}

\section{Discussion}

The present study gauged the relationship of microalbuminuria with the indices of target organ damage in nondiabetic hypertensives, a correlation between microalbuminuria and severity of hypertension and occurrence of LVH.

The prevalence of microalbuminuria in the present study was $32 \%$ (32 out of 100 hypertensive patients).Stefano Bianchi et al. in 1999 published the first large scale study on the prevalence of microalbuminuria among hypertensives; it was found to be $-35 \%$.

In this study, microalbuminuria was found to have a positive correlation with the severity of Hypertension $[\mathrm{P}=0.00614]$. In Hitha B et al study (2008)50 the prevalence of microalbuminuria was higher among those with blood pressure $>160 / 100$ than in those with SBP $140-159 \mathrm{~mm} \mathrm{Hg}$ and DBP 90-99mm $\mathrm{Hg}(46 \%$ vs $8.7 \%)$ Similar positive correlation was noted in i-SEARCH study (microalbuminuria was more prevalent with SBP $\geq 120 \mathrm{~mm} \mathrm{Hg}$, DBP $\geq 100 \mathrm{~mm} \mathrm{Hg}$ ) 
Urine Albumin Excretion and Abnormalities in LV Structure and Function

It was observed that 32 out of 100 patients had LVH [32\%] detectable by ECHO. 16 out of 28 with LVH had microalbuminuria(57.1\%).C. Tsioufis et al. [2002], in their study, observed that $21 \%$ of the 249 had LVH. LVH is reported in nearly $30 \%$ untreated hypertensives. In this study, it was observed that there is a significant correlation between the prevalence of microalbuminuria and the presence of Left ventricular hypertrophy $(\mathrm{P}<0.05)$ in hypertensive patients. The relationship between microalbuminuria and LV geometry may be due to hemodynamic or nonhemodynamic reasons. It is hypothesized that increased levels of ANP, which was secreted from hypertrophic ventricles, can directly induce microalbuminuria. The fact that heart failure patients with elevated ANP levels exhibit microalbuminuria gives further support to this view.

\section{Conclusion}

1) In this study prevalence of microalbuminuria is greater among stage 2 followed by stage 1 hypertensives, this concludes as severity of hypertension increases prevalence increases.

2) Among 28 patients with LVH ,16 patients had microalbuminuria indicating microalbuminuria is a prognostic marker for target organ damage(heart).

3) More extensive screening for microalbuminuria needs to be done in hypertensive subjects to facilitate better stratification of absolute cardiovascular risk, especially in patients with hypertension of more than five years duration.

\section{References}

1. Forouzanfar $\mathrm{MH}$ et al. Global burden of hypertension and systolic blood pressure of at least 110 to $115 \mathrm{~mm} \mathrm{Hg}, 1990-2015$. JAMA 2017 Jan 10; 317:165

2. Aram V. C., George L. B., Henry R. B., William C.C., LeeA. G., Joseph L.I. et al. The Seventh Report of the Joint National Committee on Prevention, Detection ,Evaluation\& Treatment of High Blood Pressure; JAMA: 2003; 289:2560-2571

3. Kearney PM, Whelton M, Reynolds K, Muntner, Whelton PK, He J. Global burden of hypertension:analysis of worldwide data. Lancet 2005 Jan 1521.365(9455):217-23.

4. Bakris gl, ihobanian et al. The seventh report of joint national committee on Prevention, detection, evaluation and treatment of blood pressure. The NC 7 Report JAMA289:2560, 2003.

5. Guidelines committee. 2003 ESH ESC guidelines for management of arterial hypertension J Hypertens 2003; 21: 104 53.

6. Meerzon, FZ: The Myocardium in Hyperfunction, Hypertrophy and Heart Failure, Circulation : Vol.25, 1-163,1969.

7. HithaB, Pappachan J, Pillai H, Sujathan P, Hitha B, Pappachan J, Pillai H, Sujathan P, Ramakrishna C, Jaya Prakash KMicroalbuminuria in Patients with Essential Hypertension and its Relationship to Target Organ Damage : An Indian Experience . Saudi J Kidney Dis Transpl. 2008;19(3):411-19. 